JURNAL ILMIAH KEBIDANAN IMELDA

Vol.6, No.1, Maret 2020, pp. 13-16

ISSN: 2597-7180 (Online), 2442-8116 (Print)

\title{
PENGARUH KONSUMSI BUAH PEPAYA (Carica Papaya L.) TERHADAP PENINGKATAN PRODUKSI ASI
}

\author{
Wellina BR Sebayang \\ Universitas Imelda Medan, Indonesia
}

\section{Article Info}

Keywords:

Papaya

Milk Production

Prolactin

Oxytocin

\begin{abstract}
The death of children under five in the world can be prevented through exclusive breastfeeding. Coverage of exclusive breastfeeding in Indonesia has not been satisfactory. One of the causes of the failure is the non-smooth production of breast milk, milk production and expenditure is influenced by hormones prolactin and oxytocin, and the hormone prolactin is closely related to the types of nutrients consumed. One type of nutrition that can increase the work of the hormone prolactin is papaya. This study aims to determine the effect of papaya fruit consumption on increasing milk production in postpartum mothers. Quasi experimental cohort design research methods. The intervention sample group (consuming papaya) and the control sample group each amounted to 16 respondents. The statistical test used is the man whyney test. Statistical test results were $0.003(\mathrm{p}<0.05)$. Conclusions papaya consumption affects the increase in milk production in nursing mothers. Suggestions are expected to further research with different designs for the success of exclusive breastfeeding.
\end{abstract}

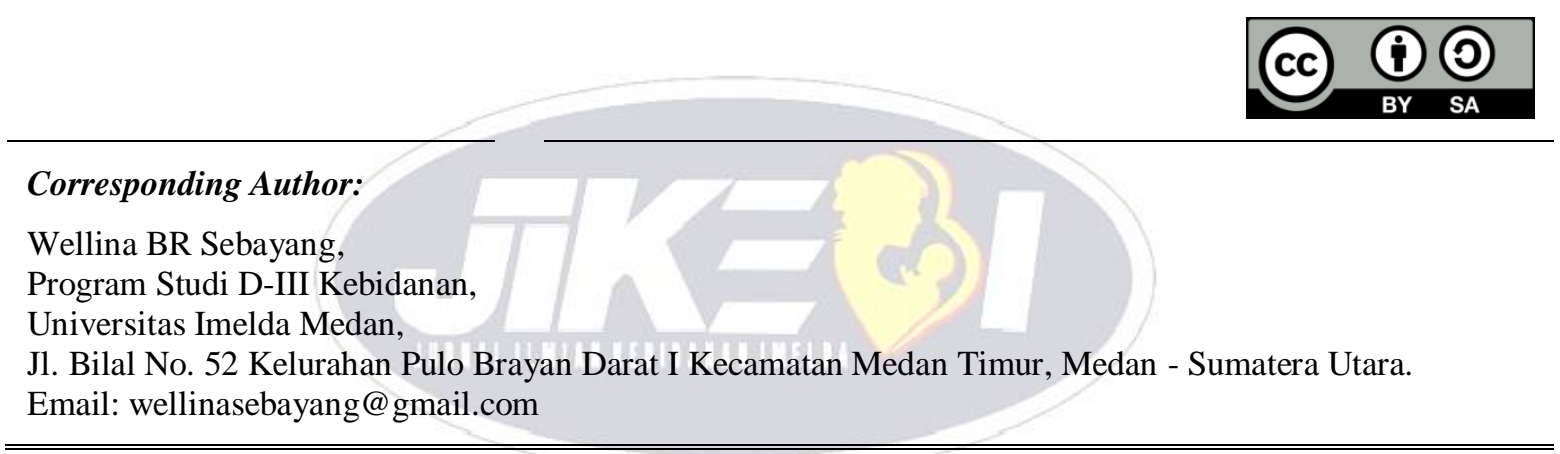

1. INTRODUCTION

Pemberian ASI kepada bayi yang baru lahir merupakan salah satu solusi yang dapat dilakukan dalam mencegah kematian bayi dan balita dan masalah kekurangan gizi. Kematian bayi balita dapat diturunkan $13 \%$ dengan cara mengefektifkan Asi ekslusif. Menurut World Health Organization (WHO) (2010) bayi baru lahir wajib diberikan ASI sampai umur 6 bulan, dan tidak boleh memberikan makanan pendamping atau cairan lain, kecuali vitamin, obat dan mineral, yang telah di sarankan karena adanya indikasi alasan medis. ASI Eksklusif adalah pemberian air susu ibu (ASI) kepada bayi tanpa diberikan makanan tambahan dan minuman pendamping sejak bayi baru lahir hingga usia 6 bulan. Sesudah bayi berusia 6 bulan baru dapat diberikan makanan tambahan pendamping ASI dengan tetap menganjurkan pemberian ASI sampai bayi berusia 2 tahun (Hartini, 2014).

Produksi Asi dipengaruhai oleh bebagai faktor, salah satu faktor yang paling berpengaruh adalah faktor hormonal, yaitu hormone prolactin dan hormone oksitosin, Hormon Prolaktin mempengaruhi produksi ASI, sementara oksitosin mempengaruhi pengeluaran ASI. Prolaktin berhubungan dengan nutrisi yang dikonsumsi ibu selama menyusui, semakin baik konsumsi nutrisi maka akan meningkat jumlah produsi ASI. 
Hormon oksitosin berhubungan dengan rangsangan atau sentuhan, semakin sering puting susu ibu dihisap bayi maka akan memperlancar proses pengeluaran ASI. (Turlina, L).

ASI mengandung banyak zat yang tidak terdapat dalam makanan maupun minuman jenis apapun, termasuk susu formula termahal dan terbaik. Pemberian ASI memberikan manfaat kepada bayi dan juga ibu. bayi yang diberi ASI berpeluang lebih rendah 25 kali untuk meninggal dunia di satu bulan pertama pasca melahirkan dibandingkan dengan bayi yang mendapat makanan tambahan selain ASI. Manfaat pemberian ASI yang besar ini mendorong pemerintah di seluruh dunia untuk mendukung keberhasilan pemberian ASI eksklusif. Dukungan pemberian ASI ini sangat diperlukan mengingat rendahnya cakupan pemberian ASI. Menurut UNICEF, cakupan rata-rata ASI eksklusif di dunia yaitu 38\%. Cakupan pemberian ASI Eksklusif di Indonesia (54,3\%) (Kemenkes, 2014). Cakupan ASI eksklusif di Indonesia masih di bawah target Indonesia Sehat 2010 sebesar 80\% (Budiharjo, 2013).

Menurut Survey Demografi Kesehatan Indonesia tahun 2013 pencapaian pemberian ASI eksklusif adalah 42\%. Persentase bayi yang memperoleh ASI eksklusif untuk usia bayi kurang 6 bulan sebesar $41 \%$, ASI eksklusif pada bayi umur 4-5 bulan sebesar 27\%, dan melanjutkan pemberian ASI sampai usia anak 2 tahun sebesar 55\% (Kementerian Kesehatan RI, 2015). Data Cakupan ASI eksklusif Susenas Provinsi Sumatera Utara tahun 2013 sebesar 56,6\%.

Menurut penelitian yang berjudul Hubungan Pengetahuan Ibu Tentang Manajemen Laktasi Dengan Pemberian ASI Eksklusif Di Rumah Sakit Imelda Pekerja Indonesia menyatakan Berdasarkan hasil penelitian diketahui bahwa dari 37 responden yang berpengetahuan baik seluruhnya memberikan ASI Eksklusif, sedangkan dari 2 orang yang berpengetahuan kurang baik, ada 2 orang yang memberikan ASI Eksklusif dan 1 orang tidak memberikan ASI Eksklusif (Hutagaol, 2018).

Penelitian sebelumnya menunjukan ada pengaruh buah papaya terhadap produksi ASI yang dilakukan pada one group eksperimen pre dan post intervensi, yaitu mean produksi ASI saat belum mengkonsumsi pepaya 5,7 kali namun setelah mengkonsumsi papaya meningkat menjadi 9,75 kali. (Istiqomah, SBT).

\section{RESEARCH METHOD}

Jenis penelitian ini merupakan quasi eksperimen menggunakan desain kohort. Sampel dibagi dalam dua kelompok, yaitu kelompok intervensi dan kelompok kontrol. Pada awal penelitian pada kedua kelompok penelitian dilakukan observasi pengeluaran ASI Tahap berikutnya: selama empat belas hari kelompok intervensi mengkonsumsi buah papaya 2-3 potong 3 kali dalam sehari (400-500 gr/hari), Pada kelompok control tidak diberikan buah papaya dan mengkonsumsi makanan seperti biasanya saja. Pada tahap akhir dilakukan kembali pengukuran pengeluaran ASI, jumlah ASI menggunakan botol ASI. Uji statistik menggunakan uji mean whytney dengan statistic kemaknaan $p$ value 0,05. Penelitian ini dilakukan di Rumah Sakit Imelda Pekerja Indonesia Medan, Jalan Bilal no 24 Pulo Brayan Darat I Medan Kecamatan Medan Timur, dilaksanakan mulai bulan Januari 2020. Populasi dalam penelitian ini yaitu ibu yang mempunyai anak usia 0-12 bulan yang berkunjung ke BKIA Rumah Sakit Imelda Pekerja Indonesia Medan, dengan tehnik asidental sampel berjumlah 32 orang responden.

\section{RESULTS AND ANALYSIS}

\subsection{Hasil}

Tabel 1. Distribusi karakteristik responden

\begin{tabular}{llcc}
\hline \multirow{2}{*}{ Karakteristik } & \multicolumn{2}{c}{ Jumlah } \\
\cline { 3 - 4 } & & $\mathbf{n}$ & $\%$ \\
\hline \multirow{2}{*}{ Umur } & $<20$ & 3 & 9,4 \\
\cline { 2 - 4 } & $20-35$ & 24 & 75,0 \\
\cline { 2 - 4 } & $>35$ & 5 & 15,6 \\
\hline \multirow{2}{*}{ Paritas } & Primipara & 19 & 50,6 \\
\cline { 2 - 4 } & Multipara & 23 & 71,9 \\
\hline \multirow{2}{*}{ Pendidikan } & SMA sederajat & 9 & 28,1 \\
\cline { 2 - 4 } & Universitas & 9 &
\end{tabular}

Dari tabel dilihat bahwa mayoritas ibu usia 20-35 tahun 75\% dan status paritas multigravida 59,4\% dengan latar belakang pendidikan paling banyak tingkat SMA sederajat 71,9\%. 
Tabel 2. Pengaruh buah papaya terhadap produksi ASI

\begin{tabular}{ccccc}
\hline Variabel & $\begin{array}{c}\text { Konsumsi buah } \\
\text { pepaya }\end{array}$ & \multicolumn{2}{c}{ Produksi ASI } & Nilai \\
\cline { 3 - 4 } & Cukup & Kurang & $p$ \\
\hline kelompok & Intervensi & 13 & 3 & \multirow{2}{*}{0,003} \\
\cline { 2 - 4 } & Kontrol & 5 & 11 & \\
\hline
\end{tabular}

Data Primer, tahun 2020

Hasil penelitian ditemukan bahwa kelompok intervensi memiliki ASI cukup sebanyak 13 reponden dan pada kelompok control hanya 5 responden. Hasil uji statistic menunjukkan $P$ value 0,03 yang berarti ada pengaruh mengkonsumsi buah papaya terhadap meningkatnya produksi ASI.

\subsection{Pembahasan}

Pepaya adalah tanaman dari family Caricaceae berasal dari negara Amerika Tengah, Hindia Barat, bahkan kawasan sekitar Costa Rica dan Meksiko. Tanaman papaya tumbuh banyak didaerah tropis dan subtropis, di daerah pegunungan kering dan basah atau dataran sampai dengan 1000 meter diatas permukaan laut. Buah pepaya memiliki gizi tinggi. Senyawa aktif yang terkandung di dalamnya yaitu enzim papain, karotenoid, alkaloid, flavonoid, monoterpenoid, mineral, vitamin, glukosinolat, dan karposida vitamin C A, B, E, sertamineral. (Kharisma, Y).

Buah pepaya memiliki efekgastro protektif, antibakterial, laksatif, dan laktagogum yang khasiatnya terlah terbukti secara ilmiah dari buah pepaya. (Nadiyah, DL) Pepaya memiliki Kandungan laktagogum (lactagogue) yang dapat menjadi salah satucara untuk meningkatkan laju sekresi dan produksiASI dan menjadi strategi untuk meningkatkan efektifitas pemberian ASI eksklusif. (Syarief, H). Hasil penelitian Muhartono, dkk menyatakan bahwa buah papaya memiliki khasiat meningkatkan produksi ASI, Mean sampel yang diteliti sebelum dan sesudah mengkonsumsi buah papaya mengalami peningkatan dari 5,7 kali menjadi 9,75 kali.

Hasil penelitian menunjukkan perbandingan yang cukup bermakna antara kelompok control dan intervensi, dimana kelompok intervensi 81,3\% memperoleh ASI yang cukup. Pada kelompok control hanya $31,3 \%$ responden dengan kategori ASI cukup. Dapat disimpulkan bahwa salah satu cara efektif meningkatkan produksi ASI adalah dengan mengkonsumsi buah papaya, cara ini cukup mudah, karena buah papaya sangat banyak dijual dipasar pasar di Indonesia dengan harga terjangkau. Buah papaya juga memiliki rasa yang manis dan segar sehingga dapat langsung dikomsumsi oleh ibu ibu menyusui tanpa harus melalui pengolahan terlebih dahulu.

\section{CONCLUSION}

Ada pengaruh mengkonsumsi buah papaya terhadap peningkatan produksi ASI.

\section{REFERENCES}

Anton Irianto, 2005 Kunci sukses yang tak pernah gagal. Jakarta, PT Gramedia Pustaka Utama.

Any Astuti, 2012. Karakteristik ibu yang berhubungan dengan pemberian air susu ibu (ASI) eksklusif pada anak usia 7-24 bulan di wilayah kerja puskesmas liwa kecamatan Balik Bukit kabupaten Lampung Barat tahun 2012. Di akses lib.ui.ac.id>file pada tanggal 28 Maret pukul 10.44

Arikunto, Suharsimi. 2010. Prosedur Penelitian Suatu Pendekatan Praktik. Jakarta: PT Rineka Cipta

Budiharjo. 2013. Hubungan Pekerjaan Dan Pendidikan Ibu Dengan PemberianAsi Ekslusif Di Wilayah Kerja Puskesmas Hinai Kiri. Di akses di http://media.neliti.com>publication (pada tanggal 13 Maret 2019 pukul 23.21)

Dahlan, A., Mubin, F., Mustika, D.N., 2013. Hubungan Pekerjaan Ibu Terhadap Pemberian Asi Eksklusif Pada Bayi. http://ejournal.kopertis10.or.id>viewFile (di akses pada tanggal 13 maret 2019 pukul 23:21)

Dinas Kesehatan Provinsi Sumatera utara. 2013. Profil Kesehatan Sumatera Utara Tahun 2013. Medan

Dwi Sunar Prasetyo, 2017 Buku pintar ASI eksklusif pengenalan, praktik, dan kemanfaatannya. Yogyakarta, DIVA Press

Fikawati, S., dan Syafiq, A. 2012. Hubungan Pekerjaan Dan Pendidikan Ibu Dengan Pemberian Asi Ekslusif Di Wilayah Kerja Puskesmas Hinai Kiri. Di akses di http://media.neliti.com>publication(pada tanggal 13 Maret 2019 pukul 23.21)

Hartini. 2014. Hubungan Pendidikan Ibu dengan Keberhasilan ASI Eksklusif Pada Bayi di Puskesmas Kasihan Yogyakarta. Skripsi. Di Akses di pac.unisayogya.ac.id/1249/1/SUSI HARTINI 213101014375NASKAH PUBLIKASI.PDF diakses pada tanggal 12 Maret 2019.

Hutagaol, A. (2018). Hubungan pengetahuan ibu tentang manajemen laktasi dengan pemberian asi eks klusif di rumah sakit imelda pekerja indonesia. Jurnal Ilmiah Kebidanan Imelda, 4(2), 565-571. 
Ida, 2011. Karakteristik ibu yang berhubungan dengan pemberian air susu ibu (ASI) eksklusif pada anak usia 7-24 bulan di wilayah kerja puskesmas liwa kecamatan Balik Bukit kabupaten Lampung Barat tahun 2012. Di akses lib.ui.ac.id>file pada tanggal 28 Maret pukul 10.44

Indriyanto, W.2015. Hubungan Antara Dukungan Keluarga Dengan Motivasi Untuk Sembuh pada Pasien Kanker yang Menjalani Kemotrapi di Ruang One Day Care RSU Moewardi, di akses dari Http://digilib.stikesusumahusada.ac.id/files/disk1/23/01-gdl-wahyudiind1113-1-0naskah -i.pdf pada tanggal 13 maret 2019 pukul 21.44

Kharisma, Y. Tinjauan pemanfaatan tanaman pepaya dalam kesehatan. Bandung: Fakultas Kedokteran Universitas Islam Bandung; 2017.

Kreitner, Robert dan Kinici. 2005. Hubungan antara karakteristik pekerjaan dengan kepuasan kerja karyawan. Di akses di http://repository.usd.ac.id>022214024 （ pada tanggal 17 Maret 2019 pukul 16.43)

Muhartono, Risti G, Gumandang H.P, Pengaruh Pemberian Buah Pepaya (Carica Papaya L.) terhadap Kelancaran Produksi Air Susu Ibu (ASI) pada Ibu Menyusui, 2018.

Nadiyah D L, Kharisma Y, Yuniarti. Penentuan derajat toksisitas akut ekstrak air buah pepaya (carica papaya l.) muda pada mencit menggunakan purposed new recommended method. Jamu Indonesia. 2016; 1 (2):15-9.

Nursalam, 2001. Karakteristik ibu yang berhubungan dengan pemberian air susu ibu (ASI) eksklusif pada anak usia 7-24 bulan di wilayah kerja puskesmas liwa kecamatan Balik Bukit kabupaten Lampung Barat tahun 2012. Di akses lib.ui.ac.id>file pada tanggal 28 Maret pukul 10.44

Notoatmojo, 2003. Karakteristik ibu yang berhubungan dengan pemberian air susu ibu (ASI) eksklusif pada anak usia 7-24 bulan di wilayah kerja puskesmas liwa kecamatan Balik Bukit kabupaten Lampung Barat tahun 2012. Di akses lib.ui.ac.id>file pada tanggal 19 Maret pukul 14.35

Rahayu S, Tjitraresmi A. REVIEW ARTIKEL: tanaman papaya (carica papaya l.) dan manfaatnya dalam pengobatan. Farmaka. 2016; 14 (1):1-17.

Setiadi.2007. Konsep \& penulisan riset keperawatan. Yogyakarta: Graha Ilmu

Suradi, Rulina dkk. Karakteristik ibu yang berhubungan dengan pemberian air susu ibu (ASI) eksklusif pada anak usia 7-24 bulan di wilayah kerja puskesmas liwa kecamatan Balik Bukit kabupaten Lampung Barat tahun 2012. Di akses lib.ui.ac.id>file pada tanggal 28 Maret pukul 10.44

Syarief H, Damanik RM, Sinaga TDoloksaribu TH. Pemanfaatan daun bangun-bangun dalam pengembangan produkmakanan tambahan fungsional untuk ibu menyusui. JIPI. 2014; 19 (April): 38-42.

\section{BIOGRAPHIES OF AUTHORS}

\begin{tabular}{|l|l|} 
Wellina BR Sebayang, Gelar D-III diperoleh dari Akademi Kebidanan Imelda Medan, \\
Jurusan Kebidanan pada tahun 2006, Gelar Sarjana diperoleh dari Universitas \\
Padjadjaran Bandung, Jurusan Bidan Pendidik Tahun 2009. Magister Kesehatan \\
diperoleh dari Universitas Sumatera Utara, Jurusan Kesehatan Reproduksi pada tahun \\
2014. Saat ini aktif sebagai dosen tetap di Prodi Kebidanan Universitas Imelda Medan.
\end{tabular}

